
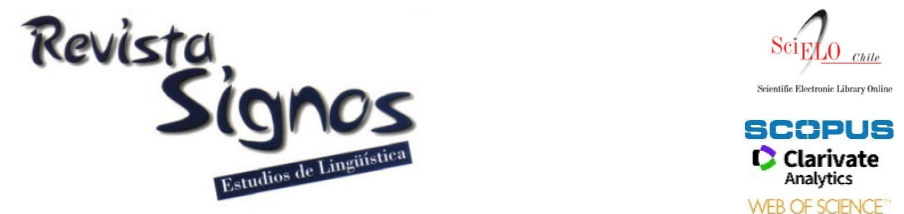

WEB OF SCIENCE

\title{
Nombres temporales: Hacia una clasificación según grados de abstracción*
}

\author{
Temporal nouns: Towards a classification according to \\ abstraction degrees
}

\section{Andreína Adelstein}

Universidad NACIONAL DE GENERAL SARMIENTO CONICET

ARGENTINA

aadelste@ungs.edu.ar

\author{
Julieta Straccia \\ UNIVERSIDAD NACIONAL DE GENERAL SARMIENTO \\ UNIVERSIDAD DE BUENOS Aires \\ ARGENTINA \\ julieta.straccia@gmail.com
}

Recibido: 04-V-2018 / Aceptado: 28-XI-2018

DOI: $10.4067 /$ S0718-09342019000200560

\section{Resumen}

La clasificación tradicional entre nombres concretos y abstractos, aunque cuestionada (Bosque \& Demonte, 1999), continúa siendo utilizada por numerosos autores de diversas perspectivas teóricas (entre los más actuales, García Meseguer, 2007; Battaner, 2017). Partimos de la hipótesis de que los nombres no se pueden clasificar como concretos o abstractos, sino que existe un continuo entre ambos polos. En el presente trabajo analizamos las resemantizaciones de un subtipo de nombres abstractos, los nombres temporales (García Meseguer, 2007) o nombres de segundo orden (Lyons, 1977; Schmid, 2000), como 'tijeretazo', con el sentido de 'recorte de recursos económicos o humanos hacia un sector o empresa' y 'blindaje', con el sentido de 'acción y efecto de proteger algo', documentados en la prensa escrita argentina, con el propósito de analizar el continuum observado en la clase de nombres abstractos temporales, a partir de un modelo de generación de sentido léxico: el Lexicón Generativo (Pustejovsky, 1995, 2011). De acuerdo con este modelo, los ítems léxicos no pueden ser clasificados como pertenecientes a una u otra categoría, ya que los sentidos se generan de modo co-composicional, a partir de la explotación de una estructura semántica infraespecificada. Hemos podido observar que la gradación de lo abstracto se refleja fundamentalmente en la estructura argumental de los sentidos generados, que impacta en la información eventiva y en la de qualia.

Palabras Clave: Nombre abstracto, nombre temporal, lexicón generativo, neología, cambio semántico. 


\begin{abstract}
The traditional classification between concrete and abstract nouns, although questioned (Bosque \& Demonte, 1999), continues to be used by numerous authors from different theoretical perspectives (among the most current, García Meseguer, 2007; Battaner, 2017). We start from the hypothesis that nouns cannot be classified as concrete or abstract, but that there is a continuum between both poles. In the present work, we analyze the resemantizations of a subtype of abstract nouns, the temporal nouns (García Meseguer, 2007) or second-order nouns (Lyons, 1977; Schmid, 2000), as 'tijeretazo', with the meaning of 'cut of economic or human resources towards a sector or company' and 'blindaje', with the sense of 'action and effect of protecting something, documented in the Argentine written press, with the purpose of analyzing the continuum observed in the class of temporal abstract nouns, from a generation model of lexical meaning: the Generative Lexicon (Pustejovsky, 1995, 2011). According to this model, lexical items cannot be classified as belonging to one or another category, since their meanings are generated co-compositionally, from the exploitation of an underspecified semantic structure. We have been able to observe that the gradation of the abstract is reflected mainly in the argument structure of the generated meanings, which impacts on the event and the qualia information.
\end{abstract}

Key Words: Abstract noun, temporal noun, generative lexicon, neology, semantic change.

\title{
INTRODUCCIÓN
}

La clasificación tradicional entre nombres concretos y abstractos, aunque cuestionada (Bosque \& Demonte, 1999), continúa siendo utilizada por numerosos autores de diversas perspectivas teóricas (entre los más actuales, Giammatteo \& Albano, 2006; García Meseguer, 2007; Battaner, 2017). Los nombres abstractos han sido relacionados con subtipos semánticos como propiedades, sensaciones, situaciones (RAE, 2009), estados, cualidades y acciones (Herrero Ingelmo, 2004). Los nombres temporales constituyen una subclase de los abstractos, y son definidos por García Meseguer (2007) como aquellos que designan eventos, sucesos instantáneos o periodos de tiempo. Se ha observado, por otra parte, que los nombres abstractos poseen diversos grados de abstracción (Lyons, 1977; Schmid, 2000) y se suele ubicar a los temporales en una zona intermedia de un posible continuum de la abstracción nominal. Lyons (1977), por ejemplo, distingue los nombres que designan entidades de segundo orden (eventos, procesos, circunstancias, ubicados en el tiempo) de los que designan las de tercer orden (como conceptos, proposiciones e ideas, que poseen un nivel mayor de abstracción, debido a que están fuera de lugar y tiempo), frente a los nombres relativos a las entidades de primer orden, que corresponden a la designación de objetos concretos. Así, los nombres de eventos, procesos y situaciones, ubicados en el tiempo, se encuentran en una zona intermedia, más cercana a los nombres concretos. En este trabajo seguimos el modelo del Lexicón Generativo (Pustejovsky, 1995; Jezek \& Pustejovsky, 2017), que permite representar el carácter temporal de los nombres en distintos niveles de representación. 
El propósito de este artículo es analizar nombres temporales, según la distribución de la información en los distintos niveles de representación de la estructura semántica, para formular una clasificación de acuerdo a grados de abstracción. Para ello partimos del análisis contrastivo entre sentidos neológicos y establecidos de nombres que en su sentido neológico se pueden clasificar como nombres temporales (García Meseguer, 2007) o nombres de segundo orden (Lyons, 1977; Schmid, 2000), como 'tijeretazo', con el sentido de 'recorte de recursos económicos o humanos hacia un sector o empresa' y 'blindaje', con el sentido de 'acción y efecto de proteger algo', documentados en la prensa escrita argentina.

En trabajos anteriores hemos estudiado subclases de nombres abstractos a partir de casos de neología semántica (Adelstein \& Straccia, 2014, 2016, 2017), que permitieron identificar la generación de sentidos de distinto grado de abstracción. El Lexicón Generativo postula una única estructura semántica infraespecificada para cada ítem léxico, sin embargo, el recurso del análisis contrastivo entre estructuras semánticas de los diferentes sentidos generados, neológicos o no, asegura una base semántica compartida que permite describir con mayor granularidad las diferencias y así identificar elementos relevantes para la determinación de subclases, en este caso las que hacen a lo abstracto. De los resultados de estos trabajos se desprende que el carácter abstracto de un sentido no sólo hace a la información del quale formal de la Estructura de Qualia, sino también a información relativa a las otras estructuras que conforman la Estructura Semántica del ítem léxico, es decir, la Estructura Argumental, la Estructura Eventiva y otros qualia de la Estructura de Qualia.

El presente estudio permite establecer grados de abstracción entre los nombres temporales y, a la vez, profundizar en la relación entre infraespecificación semántica y abstracción. La hipótesis que se pretende demostrar es que se puede establecer un continuum de abstracción entre los sentidos temporales nominales en el que el valor infraespecificado de los argumentos es la variable más relevante del carácter más abstracto.

\section{Antecedentes y marco teórico}

Se suele coincidir en señalar que los nombres concretos designan un referente percibido como material, mientras que los nombres abstractos aluden a un referente concebido como no material. Petit (2001) prefiere no realizar una distinción entre nombres concretos y abstractos, y se refiere así a usos concretos o abstractos de los nombres, ya que un mismo nombre puede tener un empleo concreto o un empleo abstracto en relación con el contexto en que aparece.

En general, las clasificaciones nominales suelen ser binarias: propios/comunes; individuales/colectivos; contables/incontables; concretos/abstractos (Bosque, 1999). La visión clásica de la categorización es discreta: un miembro pertenece a una 
determinada categoría si y solo si posee ciertas propiedades, sin posibilidad de situaciones intermedias.

Desde un enfoque cognitivo prototípico, en cambio, Martínez (2016) -que sigue la perspectiva de Rosch (2004) - señala que las clases de palabras no siempre se encuentran claramente definidas, ni son necesariamente relaciones de 'todo o nada'. En esta perspectiva de análisis, los nombres no se definen a priori como concretos o abstractos, comunes o propios, sino que participan de esquemas [+/-concretos] y [+/comunes], dependiendo de la conceptualización que se esté realizando del objeto designado en cada discurso.

Desde la filosofía, autores como Rodríguez Monsiváis (2016) han coincidido en señalar también que las entidades se encuentran ordenadas en un continuo cuyos polos van de las más concretas a las más abstractas. De este modo, el autor afirma que es posible organizar la forma en que concebimos la existencia de entidades de acuerdo a un continuo cuyos dos polos están conformados por entidades que van de lo + concreto, experimental, sensorial a lo + ideal, abstracto, formal o nocional. Señala que el significado y la referencia de un término se generan en el texto, gracias a diferentes operaciones, tanto intelectuales como lingüísticas. Así, por ejemplo, la nominalización se concibe como un mecanismo mediante el cual la lengua presenta estados, acciones o propiedades como si fueran cosas (o sustancias), y permite designar entidades más abstractas que los sustantivos concretos.

En cuanto a los nombres abstractos, se han propuesto diversas clasificaciones, atendiendo tanto a criterios semánticos como a criterios sintácticos. Goddard y Wierzbicka (en Battaner, 2017), desde una perspectiva semántica, proponen: a) nombres que significan actividades y situaciones humanas ('enfermedad', 'parricidio'); b) nombres que permiten denominar situaciones, contingencias, categorías epistémicas ('razón', 'método') y de carácter cuantitativo, como dimensiones, magnitudes, medidas ('tamaño', 'temperatura'); c) nombres que designan genéricamente conjuntos de varias clases coincidentes en su función ('perfumería', 'deporte', 'crítica'); d) nombres que denominan condiciones o situaciones sociales ('prosperidad', 'guerra'); e) nombres especializados ('estructura', 'función', 'causa', 'resultado').

Respecto de los nombres temporales, García Meseguer (2007) señala que son aquellos que pueden ser sujeto del verbo 'tener lugar' y/o aceptan la preposición 'durante'. Se pueden clasificar, a su vez, en eventivos como 'desfile' (que pueden ser sujetos del verbo 'tener lugar' y aceptan la preposición 'durante'), resultativos como 'muerte' (pueden ser sujetos del verbo 'tener lugar' pero rechazan la preposición 'durante') y durativos como 'juventud' (no pueden ser sujetos del verbo 'tener lugar' aunque aceptan la preposición 'durante').

En el presente trabajo nos proponemos explicar el continuum observado en la clase de nombres abstractos temporales, a partir de un modelo de generación de 
sentido léxico: el Lexicón Generativo (Pustejovsky, 1995, 2011). De acuerdo con este modelo, los ítems léxicos no pueden ser clasificados como pertenecientes a una u otra categoría, ya que su sentido se genera de modo co-composicional, a partir de la explotación de una estructura semántica (ES) infraespecificada, conformada por los siguientes niveles de representación: estructura argumental (EA), estructura eventiva (EE) y estructura de qualia (EQ).

En la EA se especifican los argumentos que participan y el modo en que se realizan sintácticamente. De acuerdo con este criterio, los argumentos pueden ser verdaderos (Arg), que son los que se realizan sintácticamente; por defecto (D-Arg), que son aquellos que participan lógicamente en la expresión de la EQ pero que no siempre se realizan sintácticamente; a la sombra (S-Arg), que están semánticamente incorporados al ítem léxico; y adjuntos verdaderos, que son argumentos opcionales, no ligados a la estructura lógica del ítem léxico ${ }^{1}$. Esta clasificación de los argumentos es unidimensional y se refiere a la expresión en la sintaxis. En Jezek y Pustejovsky (2017) se propone una EA dinámica, que incorpora otras propiedades relevantes de los argumentos que contribuyen a explicaciones con mayor granularidad: además de la expresión en la sintaxis ('expresado, encubierto' y 'opcional'), se propone el tipo semántico y el rol semántico. En el presente trabajo consideraremos el modo en que se expresan los argumentos en la sintaxis y observaremos, además, algunas de sus características semánticas, tales como el papel temático.

La EE, por su parte, indica el tipo de evento denotado y contiene información referente al tiempo, el espacio y la causación. De acuerdo con Pustejovsky (1991), los eventos involucrados se pueden clasificar en estados (evento simple, sin dinamismo, con duración y sin final), procesos (eventos dinámicos, con duración y sin final) y transiciones (eventos dinámicos y con final, que subsumen los logros y las realizaciones postuladas por Vendler). En Jezek y Pustejovsky (2017) se propone una estructura eventiva dinámica y se subdividen las transiciones de acuerdo con el tipo de evento involucrado. Así, las transiciones pueden ser eventos complejos formados o bien por un proceso que producen un estado (Transition $a c$ ) o bien por un estado que da lugar a otro estado (Transition acb) $^{2}$. Por otra parte, como se señala en De Miguel (1999), los eventos pueden caracterizarse tanto por su aspectualidad cualitativa como por su aspectualidad cuantitativa. Entre los rasgos que permiten caracterizar el aspecto cuantitativo de un ítem léxico se encuentra la duración con la que ocurre el evento, lo que da lugar a nombres durativos y puntuales (o escasamente durativo).

Finalmente, la EQ especifica cuatro aspectos esenciales del significado de una palabra. El quale formal (QF) distingue un objeto en un dominio más amplio, y entre sus valores se encuentran la orientación, la forma, la magnitud, el color, la posición, etc.; el quale constitutivo (QC) da cuenta de las partes que lo constituyen, el télico (QT) establece su función y el agentivo (QA) especifica los factores involucrados en su origen. 
En suma, como observa Batiukova (2006), en la ES las diversas estructuras no constituyen niveles aislados: la EE y la EA interaccionan en el sentido de que los subeventos de la EE se encuentran identificados por los argumentos de la EA; la EQ proporciona parte de su información a la EA (como el tipo semántico de argumento), la EE y la EQ interaccionan ya que determinados tipos eventivos y sus partes (subeventos) están relacionados con determinados qualia.

En cuanto a la clasificación de ítems léxicos, el Lexicón Generativo asume una jerarquía de tipos según la estructura de qualia relativizada. Para Batiukova (2006), los tipos corresponden a entidades, proposiciones (información) y eventos. Las entidades, a su vez, se pueden caracterizar como abstractas, objeto físico o artefacto. En Bouillon y Busa (2001) se subdividen, por su parte, en entidades (físico / abstracto), eventos y cualidades. Por otra parte, se suele distinguir entre tipos simples y tipos complejos, que incluyen dos componentes (por ejemplo, 'libro' incluye un componente físico y un componente informacional).

De acuerdo con trabajos previos, en los que hemos analizado diversos nombres abstractos resemantizados, lo abstracto se puede observar tanto en las entidades como en las proposiciones y los eventos. Así, en Adelstein y Straccia (2014, 2016) hemos descripto los neologismos como eventos ('calesita', con el sentido de 'modo de hacer negocios utilizando dinero para generar más dinero'), entidades abstractas (que pueden caracterizarse por una ES más o menos infraespecificada, como 'anestesia' -elemento que permite insensibilizar un hecho'- o 'convertibilidad' -referido a un sistema económico-, respectivamente) y cualidades mentales (que, al igual que las entidades abstractas, pueden tener una ES más o menos infraespecificada, como 'debilidad' -con el sentido de 'cualidad de poca intensidad'- o 'cautividad' - con el de 'estado en que el mercado mantiene a una persona'-, respectivamente). En Straccia (2017) se ha profundizado el análisis de las clases de nombres abstractos en función de la estructura argumental y en Adelstein y Straccia (2017), en relación con la estructura eventiva de dichos nombres. En este trabajo daremos cuenta del carácter abstracto de sentidos temporales de acuerdo con la interrelación de todas las estructuras de representación.

\section{Marco metodológico}

Los nombres temporales que analizamos en este trabajo forman parte de un corpus más amplio correspondiente a una investigación sobre neología de nombres abstractos detectados en el ámbito de la economía y la política, confeccionado a partir de notas periodísticas de los tres diarios de mayor circulación de la Argentina (Clarín, La Nación y Página 12) entre 2003 y 2009. Se trata un total de 256 neologismos nominales lexicográficos, es decir, el carácter neológico de los sentidos analizados se funda en el criterio de contraste con un corpus de exclusión de diccionarios del español general y del español de la Argentina ${ }^{3}$. 
Los nombres analizados en dicho corpus que en su sentido neológico son temporales (o de segundo orden) pueden clasificarse en dos grupos: (i) aquellos cuyo sentido establecido corresponde a nombres concretos ('carpa', 'corralito', 'calesita', 'burbuja'), y (ii) aquellos cuyo sentido establecido también es de segundo orden. En este trabajo analizamos exclusivamente los del segundo grupo y ampliamos el corpus textual con textos de diferentes fuentes de la prensa escrita en español posteriores a 2009. Así, el corpus final de análisis corresponde, al menos, a 20 contextos de los sentidos neológicos de los siguientes 18 nombres: 'anclaje', 'abrazo', 'balazo', 'banderazo', 'blindaje', 'bocinazo', 'bombazo', 'cachetazo', 'cañonazo', 'coletazo', 'derrame', 'derrape', 'drenaje', 'latigazo', 'maquillaje', pedaleo, 'reciclaje', 'tijeretazo'4.

Cabe aclarar que el estudio de sentidos neológicos resulta aquí una opción metodológica para detectar sentidos abstractos que presentan entre sí escasa distancia semántica, de modo de describir con mayor granularidad las diferencias entre subclases. No se trata, entonces, de un análisis de las propiedades neológicas, sino de un análisis de configuraciones semánticas generadas en contextos en el que los sentidos neológicos pueden exhibir leves variaciones en el grado de abstracción. El Lexicón Generativo propone, para cada entrada léxica, una única ES infraespecificada con distintos niveles de representación. Estos niveles resultan de utilidad para describir las particularidades de los sentidos generados y así, luego, proponer generalizaciones respecto de los niveles más relevantes de expresión de lo abstracto. De allí también la opción metodológica del análisis contrastivo entre estructuras semánticas de los diferentes sentidos generados, que corresponden a distintas configuraciones semánticas de una misma ES infraespecificada. Desde el punto de vista teórico, la formulación de distintas ES da cuenta, en última instancia, del resultado de la operación de los mecanismos generativos.

El análisis de los sentidos y de la información correspondiente a los distintos niveles de representación semántica se basa en las coapariciones de los nombres en contextos oracionales. Para detectar los distintos sentidos, establecidos o neológicos se observa la presencia de índices de generación de sentido (IGS), definidos como piezas léxicas y/o elementos léxico-gramaticales que operan mecanismos generativos dando lugar a una determinada lectura del ítem léxico (Adelstein \& Berri, 2013; Berri, 2014). Para el análisis de los tipos semánticos, entendidos como clústers de información semántica estructurada que ubica a un concepto en una ontología (por ejemplo, objeto concreto, entidad viva, lugar), utilizamos la ontología Corpus Pattern Analysis (CPA) (Hanks 2004).

\section{Análisis}

El corpus analizado está conformado por nombres temporales resemantizados derivados en '-azo' ('balazo', 'banderazo', 'bocinazo', 'bombazo', 'cachetazo', 'cañonazo', 'coletazo', 'latigazo' y 'tijeretazo'), en '-aje' ('anclaje', 'blindaje', 'drenaje', 
'maquillaje' y 'reciclaje') y formados por conversión ('abrazo', 'derrape', 'derrame’ y 'pedaleo') ${ }^{5}$. Al resemantizarse, los sentidos nuevos también son temporales y muchos de ellos, al igual que los sentidos establecidos, corresponden a tipos complejos acción - resultado, como se puede observar en el siguiente ejemplo de 'bocinazo' con el sentido de 'manifestación que consiste en tocar la bocina's:

1. Barrios de Pie realiza hoy una nueva movilización sin cortes de tránsito en distintos lugares de la Ciudad de Buenos Aires: a las 12 hubo un bocinazo en el Obelisco. (Página 12, 12/10/2017)

El Lexicón Generativo presta especial atención a los tipos complejos (también llamados dotted types o dot objects), que se caracterizan por unir en su estructura de qualia dos tipos simples relacionados de una manera específica. El ejemplo clásico 'libro’ une a través de la relación 'contener' los tipos contradictorios de objeto físico e información. Según Pustejovsky, un referente no puede ser a la vez concreto y abstracto, y por ello la única manera de explicar la existencia de un concepto complejo como 'libro' es postulando una relación que combine estos dos tipos de un modo específico. Esto explica el hecho de que puedan actualizarse ambos sentidos o facetas a la vez en un mismo contexto ('Leyó solo la mitad del libro'), o que se destaque una sola de las facetas, por ejemplo, la de objeto físico ('Limpió la tapa del libro') o la de información ('El libro fue un plagio'). Los nombres que son tipos complejos son, consecuentemente, polisémicos. Por otra parte, al ser exhibidos por miembros de una misma clase, los tipos complejos permiten explicar ciertas polisemias regulares. Por ejemplo, 'disco' y 'revista', también son tipos complejos objeto físico e información. Pustejovsky y Anick (1988) proponen así hablar de 'paradigma léxico conceptual' (plc), que agrupa los elementos que presentan un comportamiento similar en clases, como el paradigma léxico conceptual objeto físico • información.

Los datos del análisis fueron agrupados, entonces, según si los sentidos neológicos corresponden o no al mismo tipo complejo que el sentido establecido. Así, se observan, en principio, dos grupos claramente diferenciados: 1. nombres que al resemantizarse presentan el tipo complejo acción - resultado y, consecuentemente, manifiestan la misma polisemia regular, y 2. nombres que al resemantizarse presentan solo la faceta resultado.

\subsection{Nombres que al resemantizarse mantienen el tipo complejo}

Los nombres cuyos sentidos neológicos presentan el mismo tipo complejo de acción - resultado que poseen los sentidos establecidos son 'blindaje', 'latigazo', 'maquillaje', 'pedaleo', 'drenaje', 'bocinazo'. Como se puede observar en los ejemplos, la presencia de diversos elementos léxicos y gramaticales habilitan la lectura de una faceta u otra, o de ambas a la vez. Entre otros IGS, elementos como cohipónimos en relación de coordinación y la de verbos que exigen como complemento directo tipos semánticos entidades habilitan en los contextos analizados la lectura de resultado. Así, 
en 'maquillaje' la coordinación con 'vestidos' (en 2) y la presencia del verbo 'quitar' (en

3) habilitan esta lectura:

2. "Los maquillajes y vestidos del poder y la reivindicación rencorosa son una cáscara de almas que llenan su vacío triste, sobre su incapacidad de brindar caminos creativos e impiden confianza, es el vaciamiento consecuente de lo compulsivo de la soberbia, en su manifestación más torpe, que es la veleidad”. (Clarín, 25/5/2011)

3. Pues tarde o temprano, cuando se quita el maquillaje de varias estadísticas que publicó el Indec desde la intervención de Guillermo Moreno en enero de 2007, se descubre una triste verdad. (La Nación, $5 / 6 / 2016)$

Por otra parte, algunos de los IGS que generan la lectura de la faceta acción son la coordinación con nombres de acción (como en 4) y la predicación de alguna propiedad relativa a la duración de la acción (como 'más lento', en 5).

4. Decenas de automovilistas participaron esta noche de una movilización y "bocinazo" por el centro de esta Capital contra el gobernador Alberto Rodríguez Saá. (La Nación, 09/05/2004)

5. El drenaje ahora es más lento. El ritmo de cancelación de plazos fijos y cuentas a la vista en moneda extranjera se morigeró la semana pasada, cuando habrían salido unos 300 millones. Esta semana la cifra sería menor. El BCRA dará hoy los datos oficiales. (Página 12, 29/6/2012)

Finalmente, en otros casos se presentan elementos léxicos que habilitan la lectura de ambas facetas a la vez: por ejemplo, verbos que no tienen restricciones respecto de su complemento, como el verbo 'busca' en 6:

6. Maduro busca un blindaje judicial ante al avance diplomático de la oposición (La Nación, 4/6/2016)

Entre estos nombres, se observan dos subgrupos: aquellos que pueden variar su tipo semántico según el contexto y aquellos que presentan un subtipo semántico específico. A continuación se analizará cada subgrupo por separado.

\subsubsection{Nombres que al resemantizarse infraespecifican el tipo semántico}

Entre los nombres que varían su subtipo semántico en contexto se encuentran 'cañonazo' (con el sentido de 'acción y efecto de descargar'), 'blindaje 2' (como 'acción y efecto de proteger algo'), 'derrape' (con el sentido de 'acción y efecto de desviarse de lo establecido'), 'latigazo' (como 'acción y efecto de descargar'), 'maquillaje' (como 'acción y efecto de disimular un hecho y mejorar la apariencia de una situación') y 'reciclaje' (con el sentido de 'acción y efecto de someter a algo a una renovación').

Al analizar la estructura semántica de estos nombres, se ha observado que la estructura argumental del sentido establecido se mantiene en el sentido neológico 
en cuanto a la cantidad de argumentos involucrados. A modo de ilustración, véase la Figura 1 en la que se representa la EA de 'cañonazo' en sus sentidos establecido y neológico.

\section{cañonazo}

$\underline{\text { Sentido establecido }}$

S1: "disparo hecho con un cañón"

EA: Arg 1: X: ser humano

Arg 2: Y: locativo (TEMA)

S-Arg: Z: cañón (INSTR) $\underline{\text { Sentido neológico }}$

S2: "acción y efecto de descargar"

EA: Arg 1: X: infraespecificado

Arg 2: Y: infraespecificado (TEMA)

Arg 3: Z: infraespecificado (INSTR)

Figura 1. Estructura argumental de 'cañonazo'.

Sin embargo, respecto de los valores, los argumentos están infraespecificados en la ES y se señalan en contexto mediante complementos preposicionales y adjetivos: 'blindaje social', 'blindaje judicial', 'blindaje informativo', 'cañonazo de un millón de pesos', 'derrape verbal', 'derrape ideológico', 'latigazo de noticias', 'latigazo verbal', 'Iatigazo mediático', 'reciclaje de Moyano', entre otros. En cuanto al primer argumento, al infraespecificarse en la ES, puede referir en contexto a entidades que denotan un colectivo, por ejemplo instituciones como el Indec (en 7) o el conjunto de los ciudadanos (en 8):

7. Pues tarde o temprano, cuando se quita el maquillaje de varias estadísticas que publicó el Indec desde la intervención de Guillermo Moreno en enero de 2007, se descubre una triste verdad. (La Nación, $5 / 6 / 2016)$

8. Hay un "derrape ideológico de la ciudad", denuncia la oposición. (La Nación, 16/4/2017)

Por otra parte, se infraespecifican también los argumentos que cumplen los roles de tema y de instrumento: en el sentido establecido ambos son concretos, pero al infraespecificarse en el sentido neológico pueden ser abstractos. Esto se puede observar, por ejemplo, en 'blindaje': mientras en el sentido establecido ('acción y efecto de proteger con diversos materiales una cosa o un lugar') tanto lo que se protege como el instrumento con el que se lo hace son de tipo concreto, en el sentido neológico ('acción y efecto de proteger algo') los argumentos involucrados pueden ser de tipo abstracto. Por ejemplo, en 9, el adjetivo 'social' especifica el Tema como tipo abstracto y en 10, 'mediático' señala un Instrumento no concreto:

9. Un blindaje social impostergable (Página 12, 30/4/2009)

10. "El modelo de ajuste y concentración económica sólo se puede implementar con represión y blindaje mediático", sostuvo. (Página 12, $11 / 1 / 2016)$ 
En cuanto al tipo de argumentos involucrados, en aquellos nombres que poseen un S-Arg (látigo en 'latigazo', cañón, en 'cañonazo', bala en 'balazo'), este pasa a ser un argumento verdadero, lo que habilita la infraespecificación señalada más arriba. En los nombres en '-azo' que poseen sentidos establecidos de 'impacto' y 'descarga', este cambio de tipo de argumento y de infraespecificación de su valor produce que en ciertos contextos y ámbitos desaparezcan las diferencias semánticas que tienen estos nombres en su sentido establecido y puedan intercambiarse. Por ejemplo, en el ámbito del fútbol:

11. Cambiasso pegó el metrallazo para hundir el balón en la red. (Página 12, $26 / 3 / 2011)$

12. Un bombazo de García para seguir en la punta. (Página 12, 24/4/2016)

13. Maidana le aplicó un cañonazo de derecha que le movió la estantería. (Página 12, 3/5/2014)

Al modificarse el valor de este S-Arg cambia, en consecuencia, también el requisito sobre el argumento Tema, que se infraespecifica y ya no es más de tipo Locativo.

En relación con la estructura eventiva, los eventos involucrados en los nombres analizados, tanto en su sentido establecido como neológico, son, de acuerdo con Jezek y Pustejovsky (2017), transiciones estado-stado $_{\text {y transiciones }}$ proceso-estado. En términos de De Miguel (en Batiukova, 2006), se trata de T1 y L1, es decir, o bien actividades que desembocan en un cambio de estado (como 'reciclaje', 'maquillaje' y 'blindaje') o bien transiciones instantáneas de un estado a otro (como en 'latigazo' y 'cañonazo'). Como se ha señalado, tanto en los sentidos establecidos como neológicos estos nombres son tipos complejos acción - resultado, lo que se puede observar en la estructura subeventiva, que presenta dos subeventos. En la lectura de acción, el núcleo es el subevento e1, mientras que en la lectura de resultado, el núcleo es el subevento e2. Véanse en las Figuras 2 y 3 las EE de cada sentido.

cañonazo (L1 / Transiciones EST - EST)

Sentido establecido

EE: E1 $<$ E2

$\mathrm{E} 1$ = e1: proceso (disparar: núcleo: e1)

e2: estado (impactar: núcleo: e2)

$\mathrm{E} 2$ = e3: estado (dañar)
Sentido neológico

EE: E1< E2

$\mathrm{E} 1=\mathrm{e}$ : proceso (descargar: núcleo: e1)

e2: estado (impactar: núcleo: e2)

E2 = e3: estado (dañar)

Figura 2. Estructura eventiva de 'cañonazo'. 
blindaje (T1 / Transiciones PROC - EST)

$\underline{\text { Sentido establecido }}$

EE: E1<E2

$\mathrm{E} 1=\quad$ e1: proceso (blindar: núcleo: e1)

e2: estado (blindar_estado: núcleo: e2)

$\mathrm{E} 2=\mathrm{e}$ : estado (proteger) $\underline{\text { Sentido neológico }}$

EE: E1<E2

$\mathrm{E} 1=\quad$ e1: proceso (blindar: núcleo: e1)

e2: estado (blindar_estado: núcleo: e2)

$\mathrm{E} 2=\mathrm{e}$ : estado (proteger)

Figura 3. Estructura eventiva de 'blindaje'.

Los nombres que son caracterizados como T1 son definidos como actividades que desembocan en un cambio de estado, por lo cual, en cuanto a la aspectualidad cuantitativa, son durativos. En el caso de los nombres que son L1, es decir transiciones instantáneas de un estado a otro, en cuanto a la aspectualidad cuantitativa son eventos puntuales. En consonancia con el análisis que presenta De Miguel (1999) para los verbos, observamos que los nombres que poseen un aspecto cuantitativo durativo aceptan la construcción con 'durante' (como en 14) y otro tipo de construcciones temporales que aluden a la extensión del intervalo en que el evento ocurre (como en 15), lo que no es posible en los nombres puntuales. En efecto, no se han hallado en el corpus (ni al ampliar la búsqueda en Google) contextos donde 'latigazo' o ‘cañonazo' aparezcan precedidas de la preposición 'durante'. En cambio, construcciones de este tipo sí fueron observadas en los nombres T1, es decir, aquellos caracterizados como durativos:

14. La presidenta estatal del DIF, Leticia Yunes, señaló que solicitará que durante el blindaje electoral no le prohíban ejecutar el programa que ella creó por iniciativa propia. (ACP, 27/1/2018)

15. El reciclaje político en los últimos 20 años de poder político. (Manuel Dorville, 12/05/2017)

En este grupo, por lo tanto, dado que la EE se mantiene, lo que incide en el carácter abstracto de los nombres no es el tipo de evento involucrado sino los argumentos que participan en ellos.

En cuanto a la estructura de qualia, cabe señalar que el QT se mantiene, dado que el sentido neológico de muchos de estos nombres surge mediante un proceso metafórico que se basa en el QT: así, en blindaje' el QT continúa siendo 'proteger'; en 'reciclaje', 'renovar'; en 'maquillaje', 'mejorar la apariencia/disimular'; en 'cañonazo', 'dañar'. 


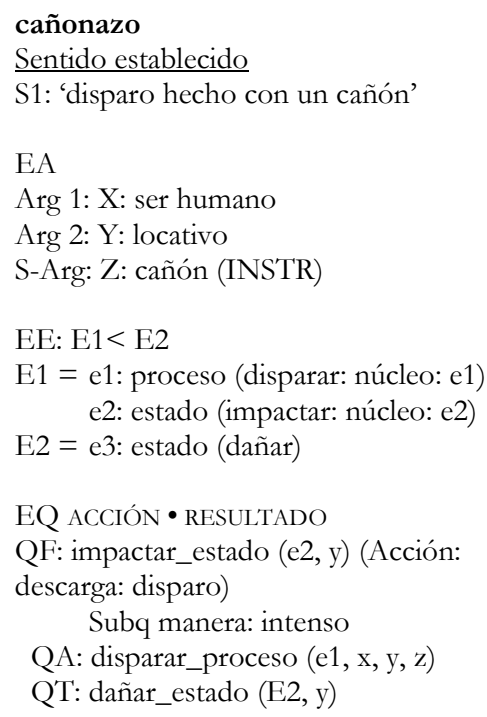

$\underline{\text { Sentido neológico }}$

S2: 'descarga que daña'

EA

Arg 1: X: ser humano

$\operatorname{Arg} 2$ : Y: infraespecificado

Arg 3: Z: infraespecificado (INSTR)

EE: E1<E2

$\mathrm{E} 1=$ e1: proceso (descargar: núcleo: e1)

e2: estado (impactar: núcleo: e2)

$\mathrm{E} 2=$ e3: estado (dañar)

EQ ACCIÓN • RESULTADO

QF: impactar_estado (e2, y) (Acción: Impacto por impacto por descarga)

Subq manera: intenso

QA: descargar_proceso (e1, x, y, z)

QT: dañar_estado (E2, y)

Figura 4. Estructura semántica de 'cañonazo'.

En relación con el QF, si bien tanto en el sentido establecido como en el neológico se representa el subevento e2 -el estado-, en los sentidos neológicos esta información se infraespecifica ontológicamente. En otras palabras, el subtipo semántico pasa a quedar infraespecificado y se interpreta en contexto. Así, por ejemplo, el subtipo semántico de 'latigazo' puede especificarse en contexto como un impacto emocional (ejemplo 16), una acusación (ejemplo 17) o como un tiro en el ámbito de fútbol (ejemplo 18).

16. Será ese detalle del que siempre se acordará alguien en una reunión en la que se hable de la movilización de este año, en un aniversario que comenzó con el latigazo que fue, especialmente para los familiares de los desaparecidos, la imagen de Macri y de un presidente de Estados Unidos internándose en el Parque de la Memoria. (Página 12, 26/3/2016)

17. "Una historia emotiva y para los jóvenes", añadió antes de explicar con un latigazo verbal por qué la presencia de Santos no lo inquietaba. (Página 12, 6/7/2013)

18. Sánchez sacó un latigazo, que fue bien desviado al tiro de esquina por Capogrosso. (Página 12, 18/3/2012)

En cuanto al QF de los nombres cuyo subquale es-un del QF es impacto por descarga ('balazo', 'latigazo', 'cañonazo'), se observa que si bien en el sentido establecido se especifica el subtipo ontológico (disparo, golpe), en el sentido neológico no se especifica ontológicamente: se trata en todos los nombres de impacto por descarga. Esta infraespecificación habilita la intercambiabilidad de estos nombres 
señalada anteriormente. De todas maneras, mantienen el subquale manera del sentido establecido, que sigue especificándose como "intensa".

\subsubsection{Nombres que al resemantizarse especifica su tipo semántico}

Otros nombres que presentan el tipo complejo acción • resultado en sus sentidos establecidos y neológicos, al resemantizarse modifican su tipo semántico que no queda infraespecificado. Los nombres de este subgrupo son, por un lado, los que se especifican como medida económica, proceso económico o financiero: 'tijeretazo' (con el sentido de 'recorte de recursos económicos o humanos hacia un sector o empresa'), 'blindaje 3' ('medida económica para proteger el dinero'), 'anclaje 3' ('medida económica que consiste en fijar el tipo de cambio'), 'drenaje' ('proceso económico que permitiría el flujo de dinero hacia otros sectores') y 'pedaleo' ('proceso financiero que permite vender una divisa con una tasa de interés baja y comprar otra con tasa de interés más alta'). Por otro lado, se encuentran nombres que se especifican como manifestación: 'bocinazo' ('manifestación que consiste en tocar la bocina'), 'banderazo' ('manifestación realizada con banderas') y 'abrazo' ('manifestación que consiste en rodear con los brazos un lugar para protestar').

El análisis de la estructura semántica permite observar que en el sentido neológico se mantiene la estructura argumental del sentido establecido en relación con la cantidad de argumentos, pero que se modifica el valor/el llenado de tales argumentos. Así, al resemantizarse, el argumento que cumple el papel de Tema (como lo recortado, en 'tijeretazo', o lo blindado, en 'blindaje'), cambia de concreto a abstracto (papel vs. recursos):

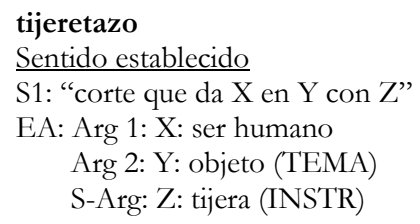

$\underline{\text { Sentido neológico }}$

S2: "recorte de X hacia Y mediante Z"

EA: Arg 1: X: organismo

Arg 2: Y: recursos económicos (TEMA)

Arg 3: Z: medida económica (INSTR)

Figura 5. Estructura argumental de 'tijeretazo'.

En los nombres con sentido de 'manifestación', el Agente pasa a ser un conjunto de personas: por ejemplo, en 'banderazo’ y ‘bocinazo’ la acción ya no se dirige hacia otro ser humano sino que la manifestación es realizada contra o a favor de una entidad o un evento. 
bocinazo (manifestación)

$\underline{\text { Sentido establecido }}$

S1: "ruido hecho con bocina"

EA: Arg 1: X: ser humano

Arg 2: Y: ser humano

S-Arg: Z: bocina (INSTR) $\underline{\text { Sentido neológico }}$

S2: "manifestación con bocinas"

EA: Arg 1: X: conjunto de personas

Arg 2: Y: entidad / evento

S-Arg: Z: bocina (INSTR)

Figura 6. Estructura argumental de 'bocinazo'.

En cuanto al tipo de argumentos involucrados, los nombres que en su sentido establecido poseen un S-Arg (tijera en 'tijeretazo', pedal en 'pedaleo'), este cambia de tipo y pasa a ser un argumento por defecto, especificado como medida económica. En los nombres con sentido de 'manifestación', en cambio, el S-Arg se mantiene (bandera en 'banderazo', bocina en 'bocinazo' y brazo en 'abrazo'), aunque como se verá se distribuyen distinto en la EQ.

En relación con la estructura eventiva, si analizamos E1, los eventos involucrados corresponden, en términos de Pustejovsky, tanto en su sentido establecido como neológico, a transiciones. En relación con la clasificación propuesta por De Miguel, el sentido establecido de estos nombres corresponde o bien a Logro 1 (como sucede con 'tijeretazo') o a Transiciones 1 ('blindaje 3', 'anclaje 3', 'drenaje' y 'pedaleo', 'abrazo', 'banderazo' y 'bocinazo'). Al resemantizarse, todos ellos son Transiciones 1, de modo que la estructura subeventiva presenta dos subeventos, que permiten la lectura del tipo complejo acción - resultado. Como vimos en los nombres del subgrupo anterior (3.1.1), en la faceta de acción, el núcleo es el subevento e1, mientras que en la lectura de resultado, el núcleo es el subevento e2:

\section{tijeretazo}

$\underline{\text { Sentido establecido }}$

(L1 / Transiciones EST - EST)

EE:

$\mathrm{E} 1=\mathrm{e} 1$ : proceso (cortar: núcleo: e1)

e2: estado (cortar: núcleo: e2)

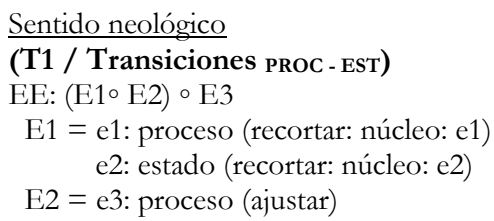

Sentido neológico

(T1 / Transiciones PROC - EST)

EE: $(\mathrm{E} 1 \circ \mathrm{E} 2) \circ \mathrm{E} 3$

$\mathrm{E} 1=\mathrm{e} 1$ : proceso (recortar: núcleo: e1)

e2: estado (recortar: núcleo: e2)

$\mathrm{E} 2$ = e3: proceso (ajustar)

Figura 7. Estructura eventiva de 'tijeretazo'.

\section{bocinazo}

$\underline{\text { Sentido establecido }}$

(T1 / Transiciones PROC - EST)

EE:

$\mathrm{E} 1$ = e1: proceso (tocar bocina: núcleo: e1) e2: estado (tocar bocina: núcleo: e2) $\underline{\text { Sentido neológico }}$

(T1 / Transiciones PROC - EST)

$\mathrm{EE}:(\mathrm{E} 1 \circ \mathrm{E} 2) \circ \mathrm{E} 3$

$\mathrm{E} 1=\mathrm{e} 1$ : proceso (manifestarse: núcleo: e1)

e2: estado (manifestarse: núcleo: e2)

$\mathrm{E} 2=\mathrm{e} 3$ : proceso (tocar bocina)

$\mathrm{E} 3=\mathrm{e} 4$ : proceso (protestar / adherir)

Figura 8. Estructura eventiva de 'bocinazo'. 
Consecuentemente, al tratarse de T1 todos los sentidos neológicos presentan una aspectualidad cuantitativa durativa. Aun 'tijeretazo' (caracterizado como puntual en su sentido establecido), al resemantizarse pasa a prolongarse en el tiempo:

19. Air Europa ha vendido 200.000 reservas durante el tijeretazo y acusa a Iberia de rozar la ilegalidad (hostelsur, 5/10/2004)

20. Sin embargo, los trenes y los aviones no pueden detener el drenaje de fondos (La Nación, 19/5/2016)

21.El hijo de Charly García increpó a Paolo Menghini durante el "bocinazo" (Clarin, 23/2/2012)

En cuanto a la estructura de qualia, estos nombres especifican sus valores en el QF y en el QT. En su sentido neológico todos siguen siendo tipos complejos, pero ontológicamente especifican el tipo semántico. Como adelantamos, algunos quedan especificados en QF como medida económica, proceso económico o financiero y otros como manifestación. Esto se observa, además, en el hecho de que se coordinan en contexto a menudo con otros nombres de tipo semántico manifestación ('participaron esta noche de una movilización y bocinazo; una caravana y banderazo'). En estos nombres, por otra parte, se observa una especificación en el subquale manera: lo que es la acción del sentido establecido ('tocar bocina' en el caso de 'bocinazo') pasa a ser la manera en el sentido neológico ('manifestarse a favor o en contra de algo tocando bocina'). Esto se relaciona con el hecho de que el proceso semántico mediante el cual se resemantizan los nombres es la metonimia.

En cuanto al QT, que es inespecífico en el sentido establecido, en los sentidos neológicos quedan especificados. Por ejemplo, un 'tijeretazo' se realiza para lograr un ajuste; un 'bocinazo', para protestar.

22. Decenas de automovilistas participaron esta noche de una movilización y "bocinazo" por el centro de esta Capital contra el gobernador Alberto Rodríguez Saá. (La Nación, 09/05/2004)

23. General Roca fue escenario de un bocinazo y en el centro de la ciudad había largas colas de autos que protestaban contra el Gobierno. ( $\mathrm{La}$ Nación, 17/06/2008) 


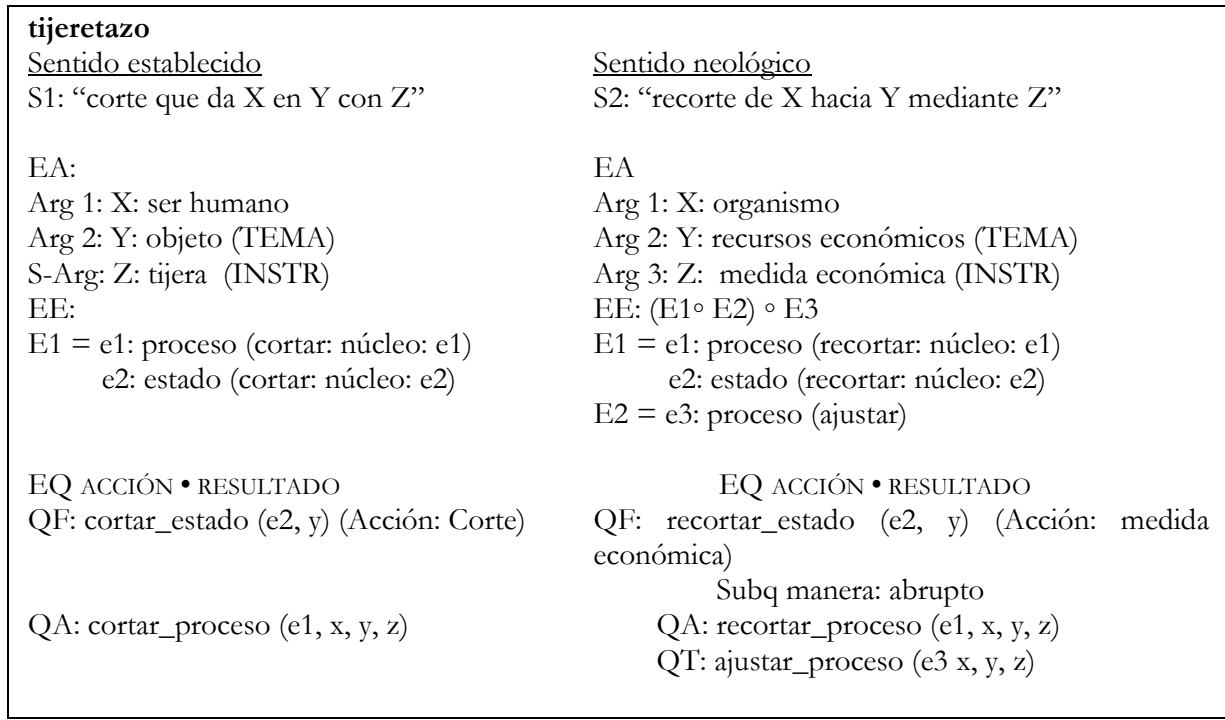

Figura 9. Estructura semántica de 'tijeretazo'.

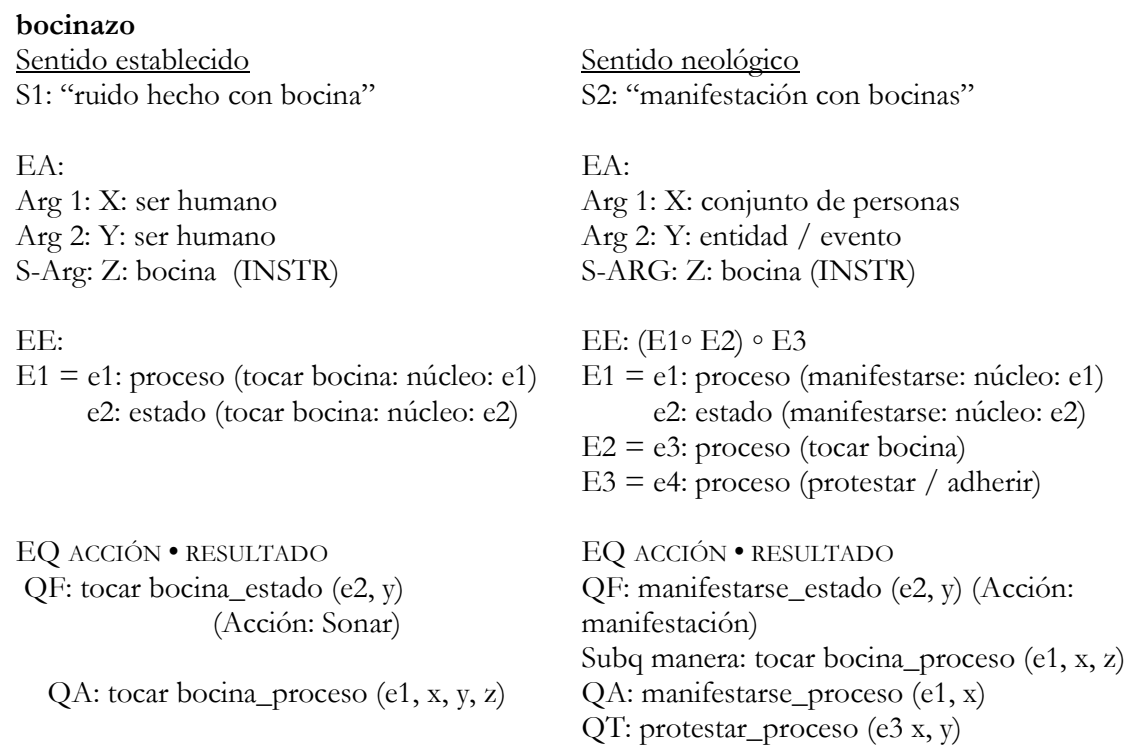

Figura 10. Estructura semántica de 'bocinazo'.

\subsection{Nombres que no mantienen el tipo complejo}

Otros nombres, en cambio, no mantienen la polisemia del sentido establecido. Así, nombres como 'anclaje', 'cachetazo' y 'coletazo', que en su sentido establecido presentan el tipo complejo acción - resultado, poseen sentidos neológicos que corresponden únicamente a una faceta, al sentido temporal resultativo. Por ejemplo, en los nombres en '-azo', la polisemia 'golpe en/con X' e 'impacto recibido', el sentido 
neológico hace a cierto impacto recibido por alguien. En efecto, los contextos en los que se han detectado los sentidos neológicos resultativos de 'efecto de fijar(se) algo en algo' ('anclaje 3'), 'hecho que conmueve' ('cachetazo' / 'coletazo') los nombres colocan con verbos de estado ('ser' en 24), estructuras de posesión ('con'/'sin', 'tener'/'faltar' en 25 y 26) y otras construcciones como 'dar'/ 'recibir', que habilitan una lectura casi de entidad (en 27):

24. La reestatización es un cachetazo a los bancos y a las AFJP. (Clarín, 26/10/2008)

25. Carrió, De Narváez, Macri, Solanas, Cobos, Reutemann y, desde ya, los mismos Kirchner, no representan más que a humores colectivos, fragmentados y pasajeros, sin anclaje identitario en sello u organización masiva alguna. (Página 12, 20/7/2009)

26. Por momentos, a su discurso de propuestas le faltó impacto, anclaje cotidiano (La Nación, 5/10/2015)

27. Troglio recibió un nuevo cachetazo: ahora lo criticó el ministro de Economía (Clarín, 13/3/2008)

Estos ejemplos evidencian además que el sentido generado es más inespecífico que la lectura resultativa del sentido establecido (por ejemplo, en 'anclaje', lo fijado puede referir a gran variedad de referentes y así especificarse en contexto). Esta observación se captura en la información semántica correspondiente a las distintas estructuras.

En cuanto a la estructura argumental, el cambio semántico conlleva una reducción del número de argumentos: desaparecen el Instrumento en 'coletazo' y 'anclaje' y el Locativo en 'cachetazo', además de que se pierde el argumento correspondiente al Agente. En efecto, la reducción de la cantidad de argumentos está en estrecha relación con el hecho de que la resemantización se produzca solo sobre la faceta resultado del tipo complejo y no respecto de la faceta acción. En cuanto al tipo de argumento, el argumento que se reduce es el S-Arg (ancla en 'anclaje', cachete en 'cachetazo' y cola en 'coletazo'). Por otra parte, en cuanto a los valores de los argumentos, se observa un cambio en las restricciones semánticas del primer argumento: en 'anclaje', los adjetivos adyacentes y otras estructuras señalan la variedad en la extensión de la referencia del poseedor (28 y 29):

28. La diferencia de once puntos de Scioli sobre Randazzo se explica en el anclaje sociodemográfico de cada candidato -analiza Bacman-. (Página $12,12 / 4 / 2015)$

29. "La clave de su éxito está en su anclaje territorial y su estructura cuasi feudal, que el radicalismo también supo tener y lo fue perdiendo", resaltó (La Nación, 23/10/2015) 
En 'cachetazo' y 'coletazo' el argumento correspondiente a quien recibe el golpe puede ser humano pero también referir a eventos (30) u organizaciones (31):

30. Dijo que no sintió el resultado "como cachetazo" y que "le quitó sentido y expectativa a la segunda elección". (La Nación, 21/9/2011)

31. Sea por la mora argentina, por el control de cambios en Venezuela o su actual escasez de divisas, el coletazo de todo esto pega de hecho en las empresas argentinas que exportan hacia allí. (Clarin, 11/8/2009)

Es decir, la información argumental se infraespecifica, tal como se representa en las estructuras de la Figura 11:

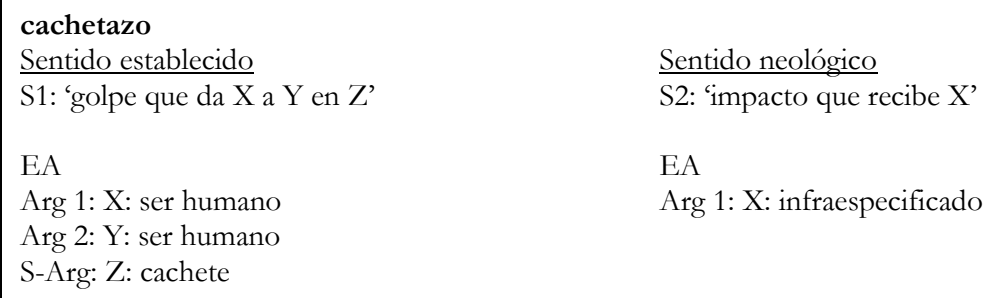

Figura 11. Estructura argumental de 'cachetazo'.

Respecto de la estructura eventiva, la resemantización del sentido establecido solo hace a una parte del tipo complejo, el resultado. Así, las lecturas del sentido establecido corresponden a transiciones en términos de Pustejovsky y a L1 ('cachetazo') y T1 ('anclaje') según De Miguel, pero en el neológico la lectura solo corresponde a Estados.

cachetazo

Sentido establecido: EE (L1)

$\mathrm{E} 1$ = e1: proceso (golpear: núcleo: e1) e2: estado (impactar: núcleo: e2)

$\mathrm{E} 2=\mathrm{e}$ : estado (lastimar)
Sentido neológico: EE (E)

EE: $\mathrm{E} 1$ = e1 = estado (impacto núcleo: e1)

Figura 12. Estructura eventiva de 'cachetazo'.

Por otra parte, en cuanto a la aspectualidad cuantitativa, presentan todos un carácter durativo. Así, mientras que en el sentido establecido 'cachetazo' y 'coletazo' son L1, eventos que carecen de duración por ser transiciones instantáneas de un estado a otro, en el sentido neológico pasan a ser nombres temporales que pueden extenderse en el tiempo.

32. Durante el cachetazo de 2008, Buffett amplió sus posesiones en Wells Fargo y US Bancorp, y compró acciones preferidas de Goldman Sachs (igdigital, 03/12/2012). 
En cuanto a la estructura de qualia, los sentidos neológicos presentan valores en el QF. Al tratarse de sentidos temporales resultativos, casi entidades, el QF es un estado. Desde una perspectiva ontológica solo se puede generalizar respecto de los nombres en '-azo', que son impactos recibidos.

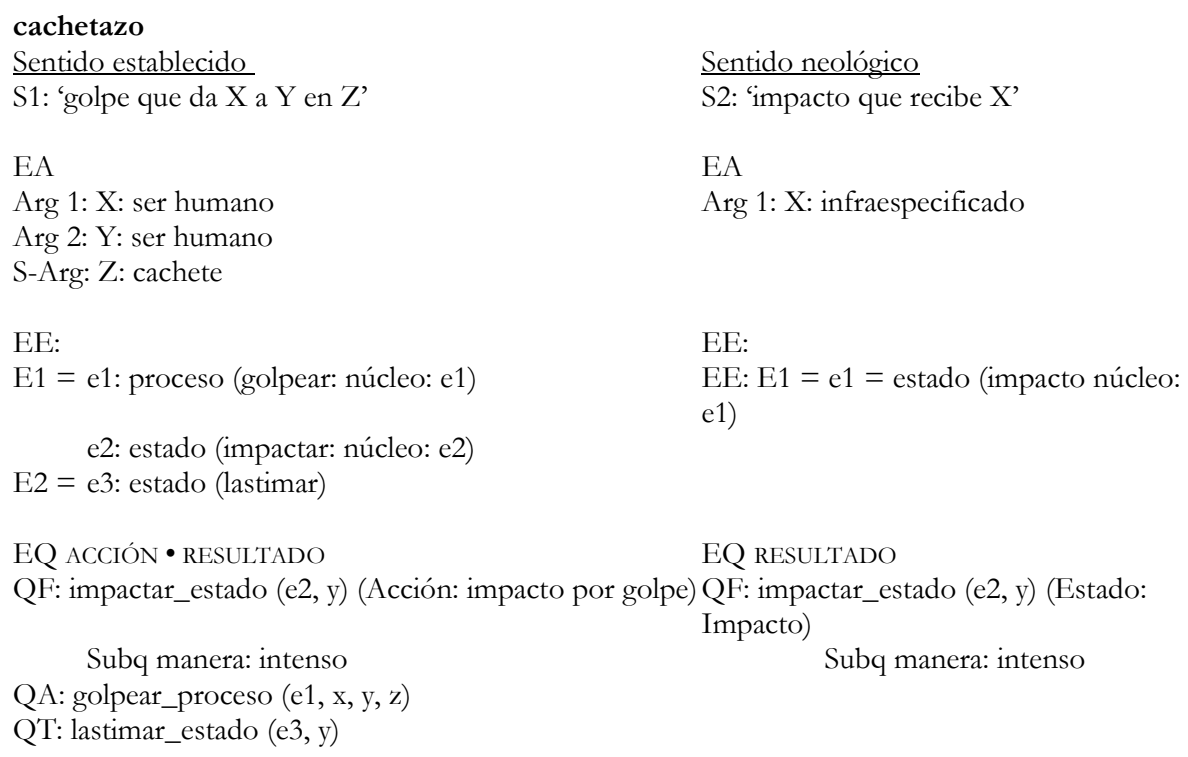

Figura 13. Estructura semántica de 'cachetazo'.

\section{Discusión}

El análisis presentado en la sección 3 ofrece elementos como para avanzar en la caracterización teórica de los siguientes aspectos de la semántica de los nombres temporales: la gradualidad del carácter abstracto de la clase y la relación entre abstracción e inespecificidad de la estructura semántica.

\subsection{Grados de abstracción en los sentidos de nombres temporales}

El análisis de los nombres temporales permite señalar que la división tradicional entre entidades de segundo y tercer orden (Lyons, 1977; Schmid, 2000), o temporales y mentales (García Meseguer, 2007), resulta insuficiente para captar los diversos grados de abstracción observados en los nuevos sentidos. Nombres como 'bocinazo', 'blindaje', 'cañonazo' y 'anclaje' son considerados en sus sentidos establecidos y neológicos nombres abstractos temporales. Sin embargo, todos ellos poseen diversos grados de abstracción. La gradación de lo abstracto se observa en la ES correspondiente a cada una de las configuraciones de los sentidos generales, fundamentalmente en la EA, que impacta en la EE y en la EQ. 
En cuanto a la estructura argumental, se ha observado que en relación con la gradación de la abstracción influyen tanto la cantidad y el tipo de argumentos involucrados como los valores que toman tales argumentos. De este modo, en los sentidos de 'efecto de fijar(se) algo en algo' y 'golpe metafórico recibido' de 'anclaje' y 'cachetazo' desaparecen algunos de los argumentos que participan en el sentido establecido (el S-Arg y uno de los argumentos verdaderos), lo que incide en el hecho de que se resemanticen solo en cuanto a la faceta de resultado, y sean considerados con un mayor nivel de abstracción, más cercanos a los nombres mentales. Por otra parte, muchos de los nombres analizados poseen en su sentido no neológico bases nominales concretas ('cañón', 'pedal', ‘tijera', 'cachete' y 'chispa') que designan el Instrumento con el que se lleva a cabo la acción ('cañonazo', 'pedaleo', 'tijeretazo'), u otros participantes del evento como el lugar ('cachetazo'). Al resemantizarse, el S-Arg modifica su tipo y pasa a ser un argumento verdadero: es el caso de ‘tijeretazo', en el cual el Instrumento deja de ser la tijera y pasa a ser una disposición. Al perder la relación con el nombre concreto que le servía de base, los referentes de estos sentidos ya no son percibidos sensorialmente y pasan a ser considerados, por lo tanto, como más abstractos. Finalmente, el cambio de sentido de los nombres temporales se observa también en relación con los valores que toman los argumentos que participan, que modifican su tipo semántico en el sentido neológico. Mientras que en los sentidos establecidos los argumentos son concretos (como, por ejemplo, en 'bocinazo', donde participan X -un ser humano-, Y -otro ser humano- y Z -la bocina-), al resemantizarse continúan participando argumentos concretos (la bocina) pero participan también argumentos colectivos, lo que, como se ha señalado, contribuye a que los hablantes los consideren más cercanos al polo abstracto. Otros nombres especifican en los sentidos neológicos sus argumentos con valores abstractos, como es el caso de 'blindaje', donde tanto lo blindado (recursos económicos) como el instrumento (medida económica) son de tipo abstracto, mientras que el argumento agentivo, al igual que en el caso de 'bocinazo', pasa a ser de tipo colectivo. Por último, en otros nombres se infraespecifican los valores de sus argumentos, por lo que pueden actualizarse como diversos tipos semánticos, como ocurre en 'cañonazo'. Por lo tanto, el carácter más o menos abstracto se relaciona en este nivel de representación de la ES de las configuraciones semánticas de un ítem léxico con el hecho de si el valor de los argumentos es concreto individual, concreto colectivo, abstracto o infraespecificado.

En cuanto a la estructura eventiva, los nombres analizados son, en su sentido establecido, Transiciones. Al resemantizarse, algunos pasan a ser Estados (como sucede en 'anclaje', con el sentido de 'efecto de fijar(se) algo en algo'), lo que contribuye al mayor grado de abstracción nominal, dado que sus referentes se acercan a las entidades abstractas, es decir, a los nombres de tercer orden. En relación con el aspecto cuantitativo de la EE, el carácter durativo o puntual no determina el grado de abstracción, pero lo hace indirectamente a través del cambio de los argumentos: 
cuando se elimina el S-Arg el sentido pasa a ser durativo y por lo tanto más abstracto, como se ha observado en 'cachetazo' con el sentido de 'hecho que conmueve'.

En cuanto a la estructura de qualia, el QF expresa el subevento estado de la EE, por lo que el carácter abstracto se observa en relación con el argumento que participa de este subevento. En cuanto al tipo ontológico, si bien todos los sentidos corresponden al tipo eventualidad, mientras que en el sentido establecido se pueden caracterizar en un nivel ontológico más específico, en el sentido neológico muchos nombres se infraespecifican y pertenecen, en consecuencia, a un lugar más alto en la jerarquía del tipo ontológico. Para capturar esta observación reformulamos aquí la ontología de la CPA (Hanks, 2004) y agregamos en la jerarquía de tipos semánticos los relevados en el análisis (desde 1.1.1.1.2. a 1.1.1.1.7 constituyen propuestas nuestras). Por ejemplo, en 'cañonazo', de acuerdo con esta ontología adaptada, se trata en su sentido establecido del subtipo disparo, mientras que en el sentido neológico el tipo ontológico ya no se especifica como disparo sino que se trata de Impacto por descarga (véase el nivel de especificación de ambos tipos en la ontología: EVENTUALIDAD EVENTO - ACTIVIDAD - ACCIÓN - IMPACTO POR DESCARGA - DISPARO).

1. EVENTUALITY

1.1. EVENT

1.1.1. ACTIVITY

1.1.1.1. ACTION

1.1.1.1.1. DECISION

1.1.1.1.2. IMPACTO POR DESCARGA

1.1.1.1.2.1. DISPARO

1.1.1.1.2.2. GOLPE

1.1.1.1.3. PROTECCIÓN

\subsection{CON OBJETO CONCRETO}

1.1.1.1.4. CORTE

1.1.1.1.5. MEDIDA ECONÓMICA

1.1.1.1.6. HACER RUIDO

\subsection{MANIFESTACIÓN}

En relación con el QA, en este nivel se expresa el subevento proceso de la EE, por lo que el grado de abstracción se relaciona con el argumento que participa en él: si el argumento que realiza la acción es colectivo, el nombre es interpretado como más abstracto. Otros nombres, en cambio, al perder algunos de sus argumentos y resemantizarse solo en la faceta resultado, pierden también el QA de su sentido establecido y son percibidos aun con un mayor grado de abstracción. Finalmente, en relación con el QT, el grado de abstracción de los nombres se vincula con el tipo semántico del argumento que se involucra en este nivel. 
El carácter abstracto se puede observar también en relación con el tipo simple o complejo del nombre: en el sentido establecido todos los nombres analizados corresponden al tipo complejo ACCIÓN $\bullet$ RESULTADO, y el resultado se puede percibir con los sentidos (como sucede en 'cachetazo'). Al resemantizarse, se modifican las características del RESULTADO, que puede ser COLECTIVO (como en 'bocinazo'), ABSTRACTO ('blindaje') o infraespecificado ('latigazo'). El modo en que es percibida la faceta RESULTADO incide en el grado de abstracción, en un continuo que va de COLECTIVO (más cercano al polo concreto) a infraespecificado (más alejado del polo concreto). Por otra parte, en otros nombres desaparece la faceta de ACCIÓN y solo se resemantiza el RESULTADO, lo que lleva a interpretar estos sentidos con un mayor grado de abstracción. En una palabra, la gradación está determinada por la presencia o no de la faceta de ACCIÓN: aquellos nombres en los que solo aparece la faceta de RESULTADO son considerados más abstractos, más cercanos a las entidades de tercer orden, ya que la ausencia de la lectura de la faceta ACCIÓN reduce el carácter temporal del sentido y, por lo tanto, el carácter más cercano a lo concreto.

En suma, se puede afirmar que el carácter abstracto se observa en la interrelación entre las distintas estructuras de cada una de las configuraciones semánticas generadas de un nombre. En la Figura 14 proponemos una gradación de los elementos que inciden en el carácter abstracto de los sentidos nominales temporales:

Estructural argumental

Tipo de Argumentos

Cantidad de Arg.

Valores de los Arg.

Estructura de Qualia

Tipo

QF

QA / QT

Estructura Eventiva

\section{+ Abstracto/-Concreto}

Sin S-Arg

Menos argumentos

Infraespecificado Abstractos Colectivos

Simple

(RESULTADO)

Eventualidad -

nivel ontológico infraespecificado

No

Estados

\section{- Abstracto/+Concreto}

S-Arg concreto

Más argumentos

Concretos

Complejo

$($ ACCIÓN・RESULTADO)

Eventualidad -

nivel más específico

Sí (relación con EA)

Transiciones

Figura 14. Relación entre estructura semántica de nombres temporales y grados de abstracción.

La caracterización de los sentidos temporales como más cercanos o alejados del polo concreto se debe fundamentalmente a las características que presenta la EA, especialmente respecto del valor de los argumentos, debido a que cuando participan argumentos con valores concretos, los referentes designados se perciben por los sentidos y se acercan, por lo tanto, a los nombres concretos (como sucede en 'cachetazo' y 'bocinazo'). Más alejados del polo concreto se encuentran aquellos 
sentidos que toman argumentos abstractos ('tijeretazo') o que infraespecifican sus argumentos ('cañonazo'). Finalmente, más cercanos a los nombres de tercer orden, o mentales, se encuentran aquellos sentidos que se resemantizan solo en la faceta RESULTADO ('anclaje'). Por su parte, el tipo ontológico, expresado en el QF, también permite caracterizar el grado de abstracción del nombre, debido a que una menor especificación del tipo ontológico se relaciona con un mayor nivel de abstracción del nombre, como se observa en 'cañonazo'.

En síntesis, los nombres temporales no exhiben de modo homogéneo el carácter +/- abstracto, sino que sus sentidos se presentan como un continuo, algunos más cercanos a los nombres de primer orden (nombres concretos) y otros más cercanos a los nombres de tercer orden (mentales). De este modo, hemos observado que los sentidos temporales analizados pueden caracterizarse en cinco niveles, independientemente de su carácter neológico:

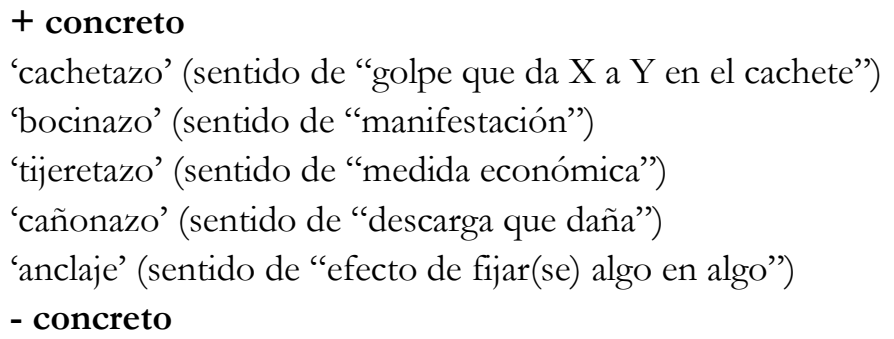

\subsection{Infraespecificación}

La infraespecificación o subespecificación (underspecification) es una propiedad de la ES del ítem léxico vinculada con la capacidad creativa del léxico, que permite fijar y especificar las distintas referencias del ítem y a la vez generar sus distintos sentidos en contexto $^{7}$. En términos de De Miguel (2009: 342) se trata de:

"la falta de especificación de las entradas léxicas que las capacita para intervenir en diferentes estructuras sintácticas y, en consecuencia, en distintas operaciones de composición semántica".

En la bibliografía, sin embargo, no se aclara cómo se expresa esta propiedad en cada uno de los niveles de representación, aunque, por ejemplo, Berri (2014) menciona que Buitelaar (1998) atribuye la representación subespecificada de la denotación a la EQ.

El trabajo sobre clases semánticas, como hemos visto, hace a los sentidos o a grupos de sentidos, y no al nombre. De hecho, en distintos trabajos se ha demostrado que en polisemias lógicas o regulares, un mismo nombre puede presentar un sentido concreto y otro abstracto. Así, respecto del carácter abstracto nominal se confirma que habría una relación estrecha entre la infraespecificación y el grado o carácter abstracto del sentido. Se puede observar que a mayor infraespecificación, mayor 
posibilidad de que un sentido sea abstracto. Esto hace especialmente a la cantidad y valor de los argumentos y al tipo ontológico en el QF. De esta manera, la estructura con menor cantidad de argumentos favorece la interpretación abstracta. El carácter abstracto también es consecuencia de la infraespecificación de los valores argumentales.

En cuanto a la información del QF, el grado de especificación se puede vincular con los niveles de una ontología. Así, un grado alto en una jerarquía ontológica habilita una mayor abstracción. Por ejemplo, en la ontología CPA reformulada que propusimos el tipo acción parece ser más abstracto porque extensionalmente habilita la posibilidad de acciones de distinto tipo (como se observa en 'blindaje', infraespecificado como 'acción y efecto de proteger' y puede luego especificarse como proceso económico o protección). En cambio, un grado más bajo en la jerarquía, corresponde a un tipo menos abstracto pues se especifica extensionalmente. Por ejemplo, acción hacer ruido, presenta un menor grado de abstracción, además, porque interviene la percepción sensorial: el instrumento o el resultado son concretos. Es decir, la extensión puede no ser abstracta. Por lo tanto, los sentidos cuyo tipo ontológico sea acción tienen un mayor grado de abstracción que los que son acción: corte, acción: manifestación; acción: medida económica o acción: hacer ruido, cuya extensión es más específica. Siguiendo a Koch y Oesterreicher (2007), se puede comprobar un continuo de abstracción donde el grado más alto de lo abstracto de un sentido corresponde a aquel cuyo valor en el QF presenta mínima intensión y máxima extensión.

Una de las particularidades semánticas más llamativas y también más conocidas de la inmediatez comunicativa es el hecho de que en ella se puede hacer referencia a un objeto preciso con ayuda de un lexema cuyo significado solo contiene rasgos semánticos muy generales, como 'objeto (físico)', 'humano', 'acción', etc. (esp. 'cosa', 'coso', 'chisme', 'hecho', 'tío', 'fulano', 'hacer', etc. ...). Tales lexemas vinculan una intensión mínima (escasa determinación del contenido) con una extensión máxima (gran capacidad de denotación). Por ello, normalmente, se denominan 'palabras comodín', nomi/verbi tutto fare, 'palabras ómnibus', 'palabras passe-partout o 'proformas' (Koch \& Oesterreicher, 2007).

\section{CONCLUSIONES}

La caracterización general de los nombres temporales y sus posibles clasificaciones se han basado fundamentalmente en el comportamiento sintáctico y la combinatoria léxica de los ítems en relación con un único sentido prototípico. Por su parte, el carácter abstracto suele aludir al tipo de referencia. Así, los temporales corresponden a un subgrupo de nombres abstractos. El análisis de nuevos sentidos nos ha permitido observar que la división tradicional entre nombres que refieren a entidades de segundo y tercer orden (Lyons, 1977; Schmid, 2000), o temporales y mentales (García 
Meseguer, 2007), resulta insuficiente para captar los diversos grados de abstracción observados.

Los resultados del trabajo permiten afirmar que el carácter abstracto de un sentido temporal se expresa en información de las distintas estructuras que conforman la ES del ítem léxico. La gradación se observa al considerar las configuraciones de los sentidos generados. En cuanto a la EA, el carácter abstracto se observa en el tipo de argumento y su valor. Respecto de la EQ, resulta relevante el valor del QF, específicamente en lo que hace a los tipos ontológicos, que se subsumen en el tipo eventualidad. En cuanto a la EE, para el carácter abstracto resulta relevante el tipo de evento, ya que los nombres que se resemantizan como Estado se encuentran ontológicamente más cercanos a los nombres de tercer orden. Por otra parte, el análisis permite incorporar en la explicación y clasificación de lo abstracto criterios relativos a la interfaz semántica-morfología (Adelstein \& Straccia, 2017) y semánticasintaxis, esto es, otros criterios además del sintáctico.

Finalmente, cabe destacar los aportes del análisis al modelo de referencia y a las ontologías respecto de los nombres eventivos, ya que se han relevado en el análisis tipos ontológicos no observados en ontologías como SIMPLE o CPA.

La formulación de distintas ES para los sentidos ha contribuido a explicar las propiedades de sentidos abstractos generados a partir de la ES infraespecificada de nombres temporales. Para completar el estudio, en futuros trabajos analizaremos las clases de IGS que inciden en contexto para la generación de los distintos grados de abstracción.

\section{REFERENCIAS BIBLIOGRÁFICAS}

Adelstein, A. (2004). Unidad léxica y valor especializado. Estado de la cuestión y observaciones sobre su representación. Barcelona: Instituto Universitario de Lingüística Aplicada, Universidad Pompeu Fabra. Colección: Serie Tesis 5.

Adelstein, A. \& Berri, M. (2013). Generación y desambiguación de sentidos en el ámbito nominal: Aportes al Léxico Generativo. Filología XLV, 95-114.

Adelstein, A. \& Straccia, J. (2014). Nombres abstractos y neología semántica. En A. Adelstein (Ed.), Interfaces semánticas (pp. 25-43). Mendoza: Editorial FFyLUNCuyo y Sociedad Argentina de Lingüística [en línea]. Disponible en: http://www.ffyl.uncu.edu.ar/spip.php?article4020

Adelstein, A. \& Straccia, J. (2016). Neología y delimitación de subclases nominales. La neología en las lenguas románicas: Recursos, estrategias y muevas orientaciones. Salamanca: Peter Lang. 
Adelstein, A. \& Straccia, J. (2017). Resemantización en nombres abstractos temporales. Ponencia presentada en el panel Clases Nominales: Semántica y aplicaciones en el I Congreso Internacional de Lexicología, Lexicografía y Terminología, Facultad de Lenguas, Universidad Nacional de Córdoba, Córdoba, Argentina.

Batiukova, O. (2006). Del léxico a la sintaxis: Aspecto y qualia en la gramática del ruso y del español. Tesis doctoral, Universidad Autónoma de Madrid, Madrid, España.

Battaner, M. P. (2017). Algunos pozos sin fondo en los diccionarios (discurso leído el 29/01/2017 en su recepción pública). Madrid: RAE.

Berri, M. (2014). Polisemia regular en nombres locativos del español. Tesis doctoral, Universidad de Buenos Aires, Buenos Aires, Argentina.

Bosque, I. (1999). El nombre común. En I. Bosque \& V. Demonte (Eds.), Gramática descriptiva de la lengua española (pp. 3-76). Madrid: Espasa Calpe.

Bosque, I. \& V. Demonte (1999). Gramática descriptiva de la lengua española. España: Espasa.

Bouillon, P. \& Busa, F. (2001). The language of word meaning. Cambridge: Cambridge University Press.

Buitelaar, P. (1998). CoreLex: An ontology of systematic polysemous classes. Proceedings of FOIS98, International Conference on Formal Ontology in Information Systems [en línea]. Disponible en: http:/ / citeseer.ist.psu.edu/viewdoc/summary?doi=10.1.1.46.3429

De Miguel, E. (1999). El aspecto léxico. En I. Bosque \& V. Demonte (Eds.), Gramática descriptiva de la lengua española (pp. 2977-3060). Madrid: Espasa Calpe.

De Miguel, E. (2009). Panorama de la lexicología. Barcelona: Ariel.

García Meseguer, Á. (2007). Nombres concretos y abstractos: Una propuesta de definición basada en pruebas sintácticas [en línea]. Disponible en: http://rua.ua.es/dspace/bitstream/10045/9936/1/ELUA_21_08.pdf

Giammatteo, M. \& Albano, H. (2006). ¿Cómo se clasifican las palabras?. Buenos Aires: Littera.

Hanks, P. (2004). Corpus pattern analysis. En G. Williams \& S. Vessier (Eds.), Proceedings of the XI Euralex International Congress (pp. 87-98). Lorient: Université de Bretagne-Sud.

Herrero Ingelmo, J. L. (2004). ¿Puede un sustantivo predicar (de los sustantivos que se pueden conjugar)?. Centro de Investigaciones Lingüísticas: Universidad de Salamanca.

Jezek, E. \& Pustejovsky, J. (2017). Dynamic argument structure, LiLT, 15, 3. 
Koch, P. \& Oesterreicher, W. (2007). Lengua hablada en la romania: Español, francés, italiano. Madrid: Gredos.

Lyons, J. (1977). Semantics. Cambridge: Cambridge University Press.

Martínez, R. (2016). Reconsideración, desde un Enfoque Cognitivo-Prototípico, del adjetivo como clase de palabra en la Lengua de Señas Argentina (LSA). Tesis doctoral, Universidad de Buenos Aires, Buenos Aires, Argentina.

Petit, G. (2001). Dénomination et léxique, French Language Studies 11. Cambridge: Cambridge University Press.

Pustejovsky, J. (1991). The syntax of event structure. En B. Levin \& S. Pinker (Eds.), Lexical and Conceptual Structure (pp. 47-181). Oxford: Blackwell.

Pustejovsky, J. (1995). The generative lexicon. Cambridge: MIT Press.

Pustejovsky, J. (2011). Coercion in a general theory of argument selection. Linguistics, 49, 6 .

Pustejovsky, J. \& Anick, P. (1988). On the semantic interpretation of nominal. Ponencia presentada en el 12th International Conference On Computational Linguistics, Budapest, Hungría.

Real Academia Española (2009). Nueva gramática de la lengua española. Madrid: Espasa Calpe.

Rodríguez Monsiváis, M. (2016). Lengua, texto y ontología. De la ontología a las operaciones textuales, HYBRIS. Revista de Filosofía, 7(1), 85-108.

Rosch, E. (2004). Principles of categorization. En E. Rosch \& B. Lloyd (Eds.), Cognition and categorization (pp. 27-48). Hillsdale, N.J.: Lawrence Erlbaum.

Schmid, H. (2000). English abstract nouns as conceptual shells: From corpus to cognition. NuevaYork: Mouton de Gruyter.

Straccia, J. (2017). Cambio semántico en nombres abstractos: Modificación en los tipos de argumentos. En A. Marcovecchio \& Y. Hipperdinger (Eds.), Asuntos gramaticales (pp. 57-68). Bahía Blanca: EdiUNS [en línea]. Disponible en: https://drive.google.com/file/d/0B8zQtKhab_oUnlSNDZ6clpYbHc/view

\section{NOTAS}

${ }^{1}$ Respecto de la traducción de los términos del modelo, seguimos los trabajos de Adelstein (2004) y De Miguel (2009). Para la formalización tanto de los niveles de la estructura semántica 
EA y EQ como de los diversos tipos de argumentos (Arg, D-Arg y S-Arg) continuamos con las siglas empleadas en trabajos anteriores. Para la EE utilizamos una formalización adaptada de Batiukova (2006).

2 De Miguel y Lagunilla (en Batiukova, 2006), por su parte, proponen clasificar las 'transiciones' de Pustejovsky en diversos tipos, de acuerdo con los subeventos involucrados: transición 1 (proceso o actividad que desemboca en un punto seguido de un cambio de estado), logro 1 (evento delimitado, transición instantánea de un estado a otro), logro 2 (evento delimitado que culmina en un punto - la fase inicial- y va seguido de un estado), logro 3 (evento delimitado que culmina en un punto -la fase inicial- y va seguido de un proceso) y transición 2 (evento delimitado, que implica una transición entre dos puntos de culminación; tanto el subevento inicial como el final pueden a su vez descomponerse en dos fases).

${ }^{3}$ El corpus de exclusión está constituido por los siguientes diccionarios:

Real Academia Española (2003). Diccionario de la lengua española (22 edición) [en línea]. Disponible en: [www.rae.es]

Battaner, P. (dir.) (2003). Diccionario de uso del español de América y España. Barcelona: VOX

Haensch, G. \& Werner, R. (dirs.) (2001). Diccionario del español de la Argentina. Madrid: Gredos

Plager, F. (coord.) (2009). Diccionario integral del español de la Argentina [DIEA]. Buenos Aires: Tinta Fresca.

4 Los sentidos neológicos de los nombres analizados presentan los siguientes sentidos: 'bocinazo' ('manifestación que consiste en tocar la bocina'); 'abrazo' ('manifestación que consiste en rodear con los brazos un lugar para protestar'); 'banderazo' ('manifestación realizada con banderas'); 'pedaleo' ('proceso financiero que permite vender una divisa con una tasa de interés baja y comprar otra con tasa de interés más alta'); 'tijeretazo' ('recorte de recursos económicos o humanos hacia un sector o empresa'); 'blindaje' ('acción y efecto de proteger algo' y 'medida económica para proteger el dinero');' anclaje' ('efecto de fijar(se) algo en algo' y 'medida económica que consiste en fijar el tipo de cambio'); 'balazo' / 'bombazo' / 'cañonazo' / 'latigazo' ('acción y efecto de descargar'); 'derrape' ('acción y efecto de desviarse de lo establecido'); 'maquillaje' ('acción y efecto de disimular un hecho y mejorar la apariencia de una situación'); 'reciclaje' ('acción y efecto de someter a algo a una renovación'); 'derrame' ('proceso económico que permitiría el flujo de dinero hacia los sectores más bajos'); 'drenaje' ('proceso económico que permitiría el flujo de dinero hacia otros sectores'); 'cachetazo' / 'coletazo' ('hecho que conmueve').

${ }^{5}$ Hemos observado que, en el caso de los nombres deverbales, el verbo de base presenta un sentido metafórico similar al del derivado, tal como lo muestran los siguientes ejemplos: 'Acusado de maquillar estadísticas.' (Página 12, 28/12/2013); 'Gran parte de los legisladores se van a reciclar políticamente.' (La Politica Online, 5/4/2015); 'La riqueza no gotea ni derrama.' (La Nación, 22/6/2011). Se podría pensar, entonces, que el proceso de resemantización se da 
en el verbo, que luego da lugar a un derivado. No obstante ello, el resultado es el de un nombre abstracto temporal.

${ }^{6} \mathrm{La}$ notación semántica que utilizamos es la siguiente: la versalitas para indicar el tipo semántico ontológico; el punto $(\bullet)$ para indicar el tipo complejo, y las comillas dobles para señalar las paráfrasis semánticas. En los ejemplos destacamos en negrita el nombre analizado y con subrayado lo que se analiza del contexto oracional.

7 Para Jayez (2001, en Berri, 2014) la representación semántica es más abstracta que las interpretaciones obtenidas en los diferentes contextos; además metodológicamente para la lingüística aplicada resulta más consistente pues subsume las posibles y difíciles de enumerar lecturas de un ítem léxico.

\section{AGRADECIMIENTOS}

* Este trabajo es resultado de los proyectos 'Clases semánticas nominales: Estudios teórico descriptivos y desarrollo aplicados’ (PIP Conicet 112 20150100062) y 'Semántica y lexicografía: Estudios en torno al nombre' (Código 30/3217, Instituto del Desarrollo Humano, Universidad Nacional de General Sarmiento).

Agradecemos las observaciones de los dos evaluadores anónimos que contribuyeron a profundizar la discusión teórica del artículo. 